\title{
Pricing Effectiveness and Regulation: An Examination of Premium Rating in Taiwan Automobile Insurance
}

\author{
Chu-Shiu Li ${ }^{\mathrm{a}}$, Chih Hao Lin ${ }^{\mathrm{a}}$, Chwen-Chi Liu ${ }^{\mathrm{b}}$ and Emilio Venezian ${ }^{\mathrm{c}}$ \\ ${ }^{a}$ Department of Economics, Feng Chia University, 100 WenHua Road, Taichung 40747, Taiwan. \\ E-mails: csli@fcu.edu.tw, andrelin39@so-net.net.tw \\ ${ }^{\mathrm{b}}$ Department of Risk Management and Insurance, Feng Chia University, 100 WenHua Road, Taichung \\ 40747, Taiwan. \\ E-mail: liuc@fcu.edu.tw \\ ${ }^{\mathrm{c}}$ Professor Emeritus, School of Business, Rutgers University, United States. \\ E-mail: Emilio_venezian@yahoo.com
}

This paper examines premium determination of voluntary automobile insurance policies and risk classification under Taiwan's heavily regulated rating system. On the basis of a unique data set, we investigate the appropriateness of the official one-size-fits-all rating formula for insurers by calculating an actual premium, a pure premium in terms of incurred loss, and a loading factor to account for different insurance coverage types. Empirical evidence indicates that there are large discrepancies between average actual premiums and average pure premiums, requiring large loading factors. The official formula captures the regular loss pattern but not excess claims, due to biased claims' behaviour. In addition, average loss ratios for all coverage types are closely correlated and profitability is high. The Geneva Papers (2010) 35, S68-S81. doi:10.1057/gpp.2010.28;

published online 20 October 2010

Keywords: risk classification; automobile insurance; premium; rating

\section{Introduction}

Premium determination is a fundamental task in the insurance industry. To conduct business and maintain solvency, insurers must set premiums based on estimated risks using available information. However, setting premiums based on observable individual characteristics such as age and gender quickly leads to challenging questions concerning business ethics, constitutional rights, and actuarial fairness. Heated debates over these questions can be traced back to the 1970s and 1980s. From the actuarial point of view, important practical problems are in the choice of estimation method and/or rating variables for setting a pure premium. ${ }^{1}$

In practice, age and gender are two major rating factors used to determine risk levels and to help set premiums in automobile insurance markets. In addition, bonus-malus systems, which take into account driving experience as a rating factor, are popular in most countries. ${ }^{2}$ Recently, adopting risk classification based on spatial data has also

\footnotetext{
${ }^{1}$ Early studies such as Chang and Fairley (1979), Weisberg and Tomberlin (1982), Coutts (1984), Jee (1989), and Stroinski and Currie (1989) are typical examples.

${ }^{2}$ Lemaire (1995).
} 
become very common. ${ }^{3}$ A fundamental question is: does a given premium reflect the cost of risk in terms of these rating factors? For example, Butler et al. provide evidence that auto insurers overcharge most women in the U.S. insurance market. ${ }^{4}$ Braver and Trempel support the view that, like younger drivers, older drivers also incur higher risks; they find that a graph of automobile losses by age is U-shaped, with lowest automobile loss costs for drivers aged $30-75 .{ }^{5}$ Brown et al. argue that using age as a rating variable in automobile insurance is acceptable discrimination under the principle of actuarial equity and the related concept of risk classification. ${ }^{6}$ According to their study, age is not used as a rating factor in six of the ten provinces of Canada, since statistical evidence shows that when age and automobile loss costs are correlated, cross-subsidisation and moral hazard problems arise.

Despite the debate on rate classification systems in auto insurance markets in western countries, the Taiwan government adopts stringent regulations on all aspects of the auto insurance industry, including minimal capital requirements, designation and approval of policies, and setting premiums for all policy types. Taiwan's insurance authority, the Taiwan Insurance Bureau, officially mandates rating formulas and standards for risk classification based on individual characteristics such as age and gender, vehicle age and type, and driving experience. Insurers cannot determine their loadings to reflect various administrative costs or operation efficiency, making the official pricing formulas a "one-size-fits-all" rating rule. ${ }^{7}$ Consumers generally choose from a varied coverage-premium menu of policies, typically paying a higher premium for greater coverage. Quotes for a particular driver will be the same for all insurers. In this environment, insurers compete mainly in terms of services and underwriting. Unable to set premiums, auto insurance companies in Taiwan behave like competing branches of a monopolistic firm. ${ }^{8}$

In Taiwan's heavily regulated market, issues concerning premium models and formulas are no less important to insurance practice. This paper explores the relationships between the auto insurance rating system and risk classification, using voluntary vehicle damage insurance data. By focusing on age and gender roles in premium determination, we examine whether the relationship between consumer payouts and losses is causal. We investigate the effectiveness of Taiwan's official one-size-fits-all rating formula by assessing its ability to incorporate claims data fairly. In addition, we analyse underwriting performance to compare loss patterns among all insurers and test consistency of loss ratios under various policy types. Finally, we discuss the implications of our findings.

Our empirical evidence indicates that there are large discrepancies between average premiums and average pure premiums, creating large values for loading factors, ranging from 1.9 to 4.8 on average. We also note that the youngest policy-holders did not have higher loss exposure as expected from the official gender-age coefficients.

\footnotetext{
${ }^{3}$ See, for example, Denuit and Lang (2004).

${ }^{4}$ Butler et al. (1988).

${ }^{5}$ Braver and Trempel (2004). In addition, Kelly and Nielson (2006) found similar results.

${ }^{6}$ Brown et al. (2007).

${ }^{7}$ The rule was deregulated starting from 1 April 2009.

${ }^{8}$ Cheng and $\mathrm{Ng}$ (1999).
} 
S70

Instead, both male and female younger policy-holders paid excessive premiums in light of these loading factors.

In an examination of the fitness of the official formula, results show that the mandatory rating formula for premiums is not suitable for all coverage types when the full policy year data is used except for Restricted Comprehensive Policy with a deductible. However, after recognising the existence of biased claim behaviour in the last policy month, we separate the data into two subgroups and find that the rating formula is consistent with claims data in the first 11 months for both All Peril Comprehensive Policy and Restricted Comprehensive Policy with deductible. We find that the standard rating formula, with fixed rating factors and coefficients, is capable of capturing the regular loss pattern but not the excess claims due to biased claims behaviour in the last policy month. Nonetheless, the estimated basic premium in this study for each policy type disagrees with the theoretical value adjusted by Taiwan's insurance authority every few years, indicating that policy-holders may be overcharged for coverage.

Finally, we examine the performance of insurers. We find that the average loss ratios for all coverage types are closely correlated by the insurer. Insurers with a good loss ratio for one contract type should be able to maintain similar performance for other contract types. All insurers maintain loss ratios below 33 per cent for Moving Vehicle Collision Policy, and two-thirds of insurers maintain loss ratios below 50 per cent for the other policies, confirming insurer profitability in this market, due to the one-size-fits-all rating formula.

\section{Automobile insurance system in Taiwan}

Taiwan launched its present rating system for vehicle damage coverage in 1996. As part of this system, the insurance authority determines rating formulas, rating factor weights, bonus-malus components, and loading factors. Since all insurers comply with the same operating rules and submit monthly reports on every auto insurance transaction, available data for our study is comprehensive. The official rating formula for vehicle damage policies is:

$$
\begin{aligned}
\text { actual practual premium }= & \text { basic premium } \times \text { insured coefficient } \\
& \times \text { manufacture coefficient },
\end{aligned}
$$

where basic premium involves a loading factor $\lambda$.

The manufacture coefficient is highly correlated with vehicle type and age. Each car is assigned an initial coefficient based on vehicle make and model. This initial value is then adjusted by age: older vehicles have smaller manufacturing coefficients. ${ }^{9}$ The insured coefficient is composed of two parts: immutable characteristics (gender and age) as shown in Table 1 and past driving experience in terms of bonus-malus points. In Table 1, gender-age coefficients vary by both age and gender. For a given age, males

\footnotetext{
${ }^{9}$ The manufacture coefficient can be adjusted by -0.05 for vehicles less than two years old, -0.10 for vehicles more than two but less than three years old, and -0.15 for vehicles more than three years old.
} 
Table 1 Gender-age coefficients in premium rating system

\begin{tabular}{llr}
\hline Age & Male & Female \\
\hline Under 20 & 1.89 & 1.70 \\
Over 20 but under 25 & 1.74 & 1.57 \\
Over 25 but under 30 & 1.15 & 1.04 \\
Over 30 but under 60 & 1.00 & 0.90 \\
Over 60 but under 70 & 1.07 & 0.96 \\
Over 70 & 1.07 & 0.96 \\
\hline
\end{tabular}

Table 2 Average premium and pure premium by coverage type in policy year 2003

\begin{tabular}{lrrrr}
\hline Coverage type & Form A & Form B_D & Form B_NoD & Form C \\
\hline Number of policies & 14,835 & 38,101 & 146,592 & 109,368 \\
Market share (per cent) & 4.80 & 12.33 & 47.46 & 35.41 \\
Claims & 5,013 & 11,781 & 50,205 & 7,394 \\
Average claim rate (per cent) & 33.79 & 30.92 & 34.25 & 6.76 \\
Basic premium (NT\$) & 47,096 & 23,119 & 25,433 & 11,918 \\
Average premium & 47,442 & 24,006 & 24,503 & 10,147 \\
Average pure premium & 15,569 & 8,345 & 7,725 & 1,751 \\
Calculated loading & 2.047 & 1.877 & 2.172 & 4.796 \\
\hline
\end{tabular}

have a higher rating coefficient than females, ranging from nine per cent higher for those aged over 30 but under 60 to 19 per cent higher for those aged under 20 .

The key element in the bonus-malus system, the claims coefficient, is obtained by the conversion of cumulative claim points, calculated as the sum of no-claim points and claim points in the past three years. In general, the marginal change in the premium for each additional claim is 20 per cent. In the case that a driver in a claim is not the policy-holder, the claim point is still counted against the policy-holder. Similarly, each no-claim year corresponds to a 20 per cent discount. The official loading factor permitted by Taiwan's insurance authority is 34.5 per cent.

There are four major types of coverage for vehicle damage: Form A (All Peril Comprehensive), Form B with deductible (Form B_D, Restricted Comprehensive), Form B with no deductible (Form B_NoD, Restricted Comprehensive), and Form C (Moving Vehicle Collision). Form A covers all specified risks with compulsory increasing per-claim deductibles, while Form $\mathrm{C}$ covers only one moving collision risk with no deductible. The only difference between Form A and Form B is that Form A covers unknown perils. Basic premiums are highly variable across policy types (see Table 2), with the basic premium for Form A around two times that of Form B and around four times that of Form $\mathrm{C}$.

\section{Empirical analysis}

This section considers three empirical tests. We first evaluate the effectiveness of the official rating formula by calculating the actual loading factors of all policy types using 
cost-based pricing. Second, we use regression analysis to assess its appropriateness. Third, we examine insurer operating performance for various policies.

\section{Data}

We analyse a unique data set of all transactions concerning private automobile vehicle damage insurance contracts in Taiwan for policy year 2003.

As shown in Table 2, Form B_NoD was the most popular policy type, representing 47 per cent of the market share. In contrast, Form A represented less than five per cent of the market share, indicating low demand for comprehensive coverage with higher premiums. Among all policy types, Form $\mathrm{C}$ policy has the lowest average claims frequency (seven per cent), suggesting that limited coverage moderates excess claims. In contrast, the other three policy types have similar average claims frequencies (more than 30 per cent) regardless of coverage.

\section{Measuring loading factors}

We first derive the loading factors for all types of automobile insurance policies. The premium setting by the insurers can be expressed in terms of pure premium and loading expense. The pure premium is defined as the expected cost of incurred claims, which is the product of the claim frequency and the claim severity. We calculate the loading factor from our retrospective data set using average terms. ${ }^{10}$

Figure 1 shows the average premium and average pure premium for each coverage type by policy-holder age. The curves of average premium for each policy type are L-shaped, suggesting that the average premium is higher for policy-holders under 30 years of age but is lower for policy-holders over 30 . The last three rows of Table 2 report the average premium, average pure premium, and loading factors for each coverage type. As expected, the average premiums for all coverage types are closely related to corresponding basic premiums. However, we find large discrepancies between average premiums and average pure premiums, with the largest discrepancies for younger policy-holders. These discrepancies create large loading factors, ranging from 1.9 for Form B_D to 4.8 for Form C. Figure 2 shows the loading factors by age for each coverage type, confirming the higher loading factors for Form $\mathrm{C}$ policies.

\section{Assessing effectiveness of the official rating formula}

Since Taiwan's insurance authority determines all rating formulas, including rating factor weights and loading factors, we examine the consistency of observed premiums with the official formula. This is investigated by log-transforming Eq. (1) to obtain the regression model:

$$
\log (A P)=a+b \log (A I)+c \log (A M)
$$

\footnotetext{
${ }^{10}$ Loading factor $=($ average premium/average pure premium $)-1$, where the average premium is the total premium divided by the number of policies and the average pure premium is the total cost of incurred claims divided by number of policies.
} 
Form A

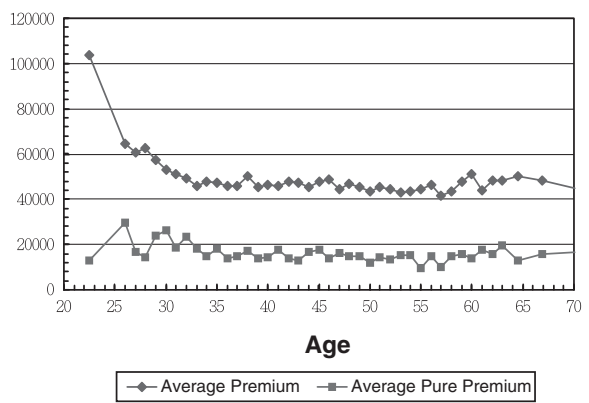

Form B_NoD

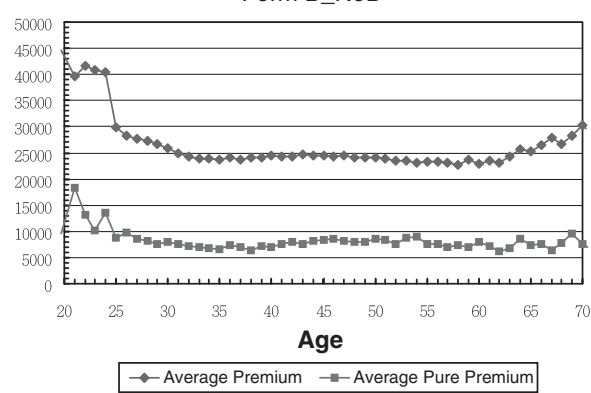

Form C

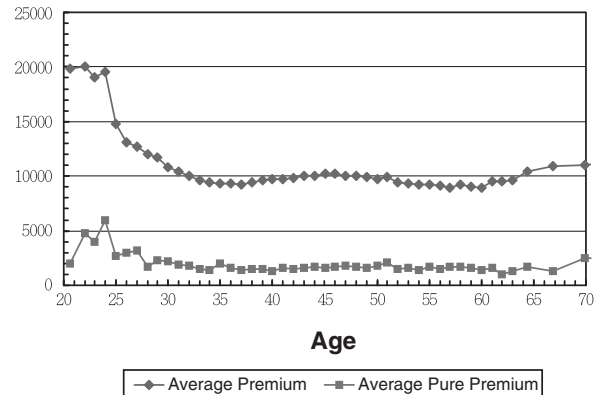

Form B_D

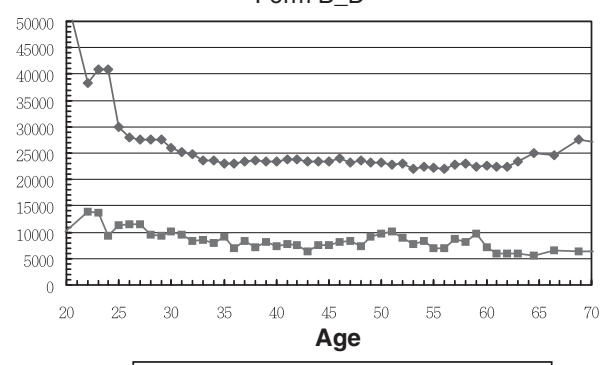

$\rightarrow-$ Average Premium $\rightarrow-$ Average Pure Premium

Figure 1. Average premium and average pure premium by age.

where $A P$ is the average incurred loss of the group; $A I$ is the average insured coefficient of the group, taking into account gender, age, and the claim coefficient; $A M$ is the average manufactured coefficient of the group. To test whether the observed premiums are consistent with the official rating formula, we employ an $F$-statistic to test the null hypothesis $H_{0}: b=c=1$. If the formula is not consistent with the data, either $b$ or $c$ (or both) will be different from one.

In practice, excess zero claims in automobile insurance are very common. Extensive literature has examined this issue by fitting the claim frequency with a specific distribution. ${ }^{11}$ We observe a similar phenomenon: numerous policies report no claims during the policy period. Consequently, to estimate the regression model, we rank policies by their actual premium, grouping adjacent policies to form groups of approximately equal claims amounts. The descriptive statistics of grouping data are shown in Table 3. Note that there are large differences in the number of groups when compared across policy types, ranging from 109 for Form A to 1,004 for Form B_NoD. ${ }^{12}$

The initial tests using the full period year are shown in Table 4 . The null hypothesis is rejected for all policy types except Form B_D. In other words, the insured coefficient

${ }^{11}$ See, for example, Yip and Yau (2005).

12 The grouping method is robust and stable. We have included different average claims numbers in a group such as 25,50 , and 75 ; the variation in coefficients estimated is small. The major findings remain the same. Tables 3-5 report the results when the target number of claims was 50 in each group. 
Form A

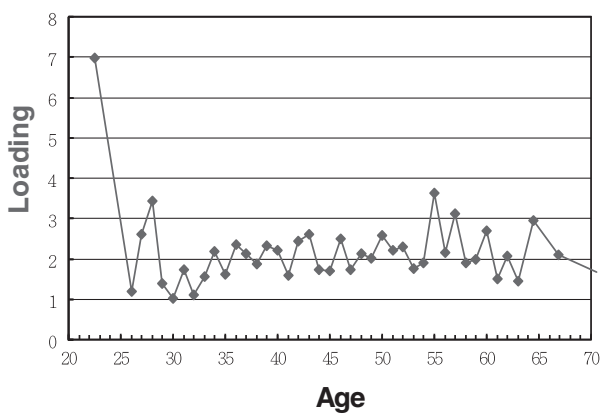

Form B_NoD

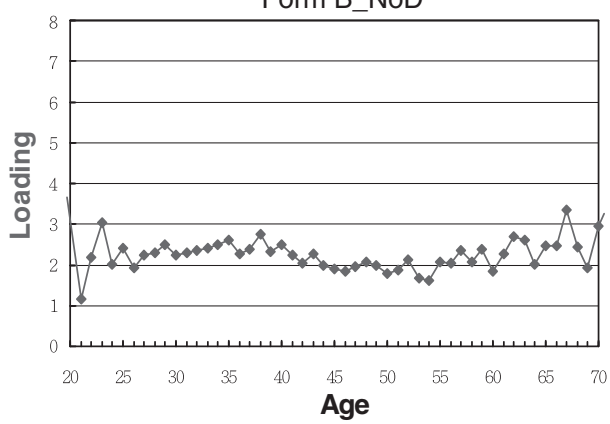

Form C

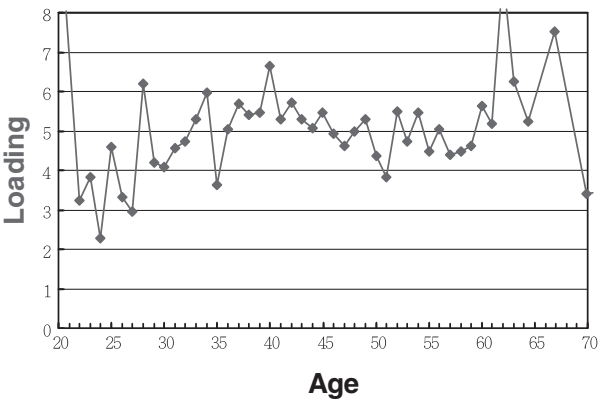

Form B_D

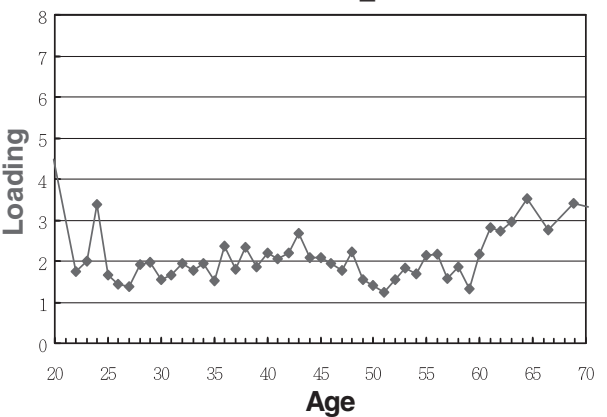

Figure 2. Loading by age.

Table 3 Descriptive statistics of grouping data

\begin{tabular}{|c|c|c|c|c|}
\hline Coverage type & Form A & Form $B_{-} D$ & Form $B_{-}$NoD & Form $C$ \\
\hline Number of policies & 14,835 & 38,101 & 146,592 & 109,368 \\
\hline Number of groups & 109 & 256 & 1,004 & 148 \\
\hline \multicolumn{5}{|c|}{ Number of policies per group } \\
\hline Max & 314 & 579 & 2,228 & 1,573 \\
\hline Min & 76 & 31 & 24 & 39 \\
\hline Ave & 136.10 & 148.83 & 146 & 738.97 \\
\hline \multicolumn{5}{|c|}{ Number of claims per group } \\
\hline Max & 49 & 51 & 54 & 51 \\
\hline Min & 43 & 44 & 47 & 44 \\
\hline Ave & 46 & 46 & 50 & 50 \\
\hline
\end{tabular}

and manufacture coefficient fail to reflect the real claims patterns for policy-holders for Forms A, B_NoD, and C. However, we do not find evidence that the official formula is inconsistent with Form B_D.

One complication with direct interpretation of our empirical results is that before the present auto insurance regulation system was implemented, Form A was the only policy type available. Form B_D, which does not cover unknown perils as in Form A, was 
Table 4 Results of regression analysis for grouped policies in policy year 2003

\begin{tabular}{lcccr}
\hline & Form $A$ & Form $B_{-} D$ & Form B_NoD & Form C \\
& $(1)$ & $(2)$ & $(3)$ & $(4)$ \\
\hline$a$ & 9.8693 & 9.3433 & 9.5833 & 7.8704 \\
$\mathrm{TV}$ & 11.0600 & 10.3490 & 10.4439 & 9.6859 \\
$\operatorname{Pr}(t)$ & 0.0000 & 0.0000 & 0.0000 & 0.0000 \\
$b$ & 0.7672 & 1.2063 & 1.1757 & 3.1441 \\
$c$ & 0.9672 & 0.8082 & 0.3801 & -0.0647 \\
$\operatorname{Pr}(F)$ & 0.0161 & $\mathbf{0 . 3 8 9 6}$ & 0.0000 & 0.0000 \\
$R^{2}$ & 0.8155 & 0.4591 & 0.0974 & 0.3989 \\
\hline
\end{tabular}

Notes: $\operatorname{Pr}(t)$ and $\operatorname{Pr}(F)$ represent p-values for tests that $H_{0}: a=\mathrm{TV}$ (theoretical value) and that $H_{0}: b=c=1$.

introduced in 1996 to mitigate heavy losses from Form A coverage. ${ }^{13}$ As a special insurance contract to reimburse the insured for any loss, covering unknown perils creates significant incentive for policy-holders to file excess claims at the end of the policyperiod. ${ }^{14}$ On the basis of this irregular claims phenomenon, it is not surprising that the official formula is not consistent with loss patterns for Form A. This may help explain why loss patterns for Form B_D are more consistent with the official rating formula.

Form $\mathrm{A}$ is not the only policy to have excess claims filed extensively at the end of the policy period. According to a recent study, expiration date effects are widespread in Taiwan's automobile insurance market. ${ }^{15}$ As Figure 3 shows, all policies reveal high peaks in monthly shares of claims ratios in the last policy month, reaching as high as 35 per cent of all claims in the 2003 policy year. To take into account this temporal pattern, we consider two additional implementations of Eq. (2): one based on the annualised average incurred loss for the first 11 policy months and one based on the annualised incurred loss in the last policy month. Table 5 presents results of these two analyses. On the basis of data of the first 11 policy months (columns 1 and 3), we find no evidence that premiums are inconsistent with the official rating formula for coverage Forms A and B_D (columns 1 and 3). On the other hand, based on the claims data in the last policy month (columns 2 and 4), there is strong evidence that the official rating formula is inconsistent with observed incurred losses. In other words, the official formula fails to capture the irregular claims pattern in the last policy month.

For the other two forms of coverage, Form B_NoD and Form C (columns 5 through 8), the official formula is also inconsistent with observed loss patterns for both the first 11 months and the $12^{\text {th }}$ month. Since all four policy types use the same rating factors and related coefficients, we examine whether the official basic premium in Table 2, divided by the loading factor, is consistent with the estimated results for Form A and Form B_D (column 2 in Table 4 and columns 1 and 3 in Table 5). For Form B_NoD and Form C the examination is of no interest because the regressions do not fit well. In Eq. (2), the value of the intercept should, in theory, be equal to the basic

\footnotetext{
13 See Wang (2004) for details.

${ }^{14} \mathrm{Li}$ et al. (2008).

${ }^{15} \mathrm{Li}$ et al. (2007).
} 


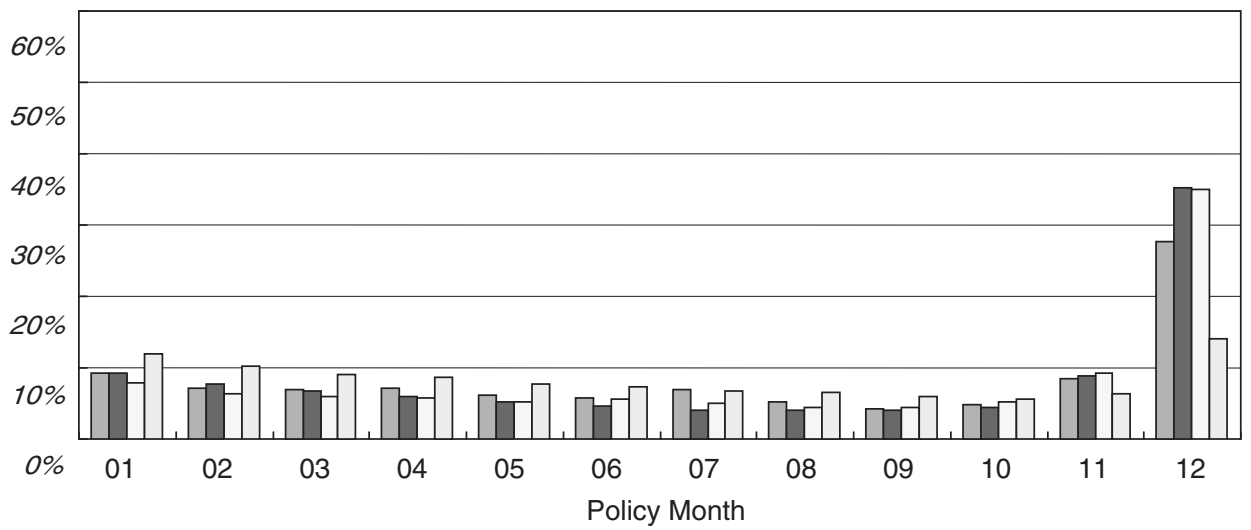

$\square$ Form A $\quad \square$ Form B_NoD $\square$ Form B_D $\quad \square$ Form C

Figure 3. Monthly shares of total claims in policy year 2003.

Table 5 Results of regression analysis for grouped policies: Two subperiods

\begin{tabular}{|c|c|c|c|c|c|c|c|c|}
\hline \multirow[t]{3}{*}{ Months } & \multicolumn{2}{|c|}{ Form $A$} & \multicolumn{2}{|c|}{ Form $B \_D$} & \multicolumn{2}{|c|}{ Form B_NoD } & \multicolumn{2}{|c|}{ Form $C$} \\
\hline & (1) & (2) & (3) & (4) & (5) & (6) & (7) & (8) \\
\hline & $1-11$ & $12 \mathrm{th}$ & $1-11$ & $12 t h$ & $1-11$ & $12 t h$ & $1-11$ & $12 t h$ \\
\hline$a$ & 9.7551 & 8.1148 & 8.9891 & 7.8061 & 9.0034 & 7.6533 & 7.7381 & 5.1616 \\
\hline TV & 10.9730 & 8.5751 & 10.2615 & 7.8636 & 10.3569 & 7.9590 & 9.5989 & 7.2010 \\
\hline $\operatorname{Pr}(t)$ & 0.0000 & 0.0018 & 0.0000 & 0.1688 & 0.0000 & 0.0000 & 0.0000 & 0.0000 \\
\hline$b$ & 1.0750 & 1.9318 & 0.8996 & 1.6087 & 0.9202 & 1.2907 & 2.7909 & 3.2465 \\
\hline$c$ & 0.9477 & -0.9637 & 1.1587 & -0.1020 & 0.5293 & -0.0717 & 0.0727 & -0.5724 \\
\hline $\operatorname{Pr}(F)$ & 0.9666 & 0.0000 & 0.3006 & 0.0000 & 0.0000 & 0.0000 & 0.0000 & 0.0022 \\
\hline$R^{2}$ & 0.8376 & 0.5330 & 0.7388 & 0.5912 & 0.2814 & 0.1316 & 0.7069 & 0.2834 \\
\hline
\end{tabular}

Notes: $\operatorname{Pr}(t)$ and $\operatorname{Pr}(F)$ represent p-values for tests that $H_{0}: a=\mathrm{TV}$ (theoretical value) and that $H_{0}: b=c=1$.

premium divided by the loading factor. The comparison of these values provides another measure of whether the actual premium matches that of the pure premium. The results of this comparison are shown in the first three lines of Table 4. For example, column 2 in Table 4 shows that the estimated intercept is 9.3 while the theoretical value is 10.3 . This implies that either the official basic premium is close to twice the actual basic premium or the actual loading is far beyond the official value of $0.345{ }^{16}$ This value falls within the 95 per cent confidence interval for the loading

\footnotetext{
${ }^{16}$ From Table 4, the difference between theoretical value and the intercept is 1.006 for Form B_D. If the difference between estimated and theoretical value on intercept of $\log$ regression is 1 , after manipulating
} 


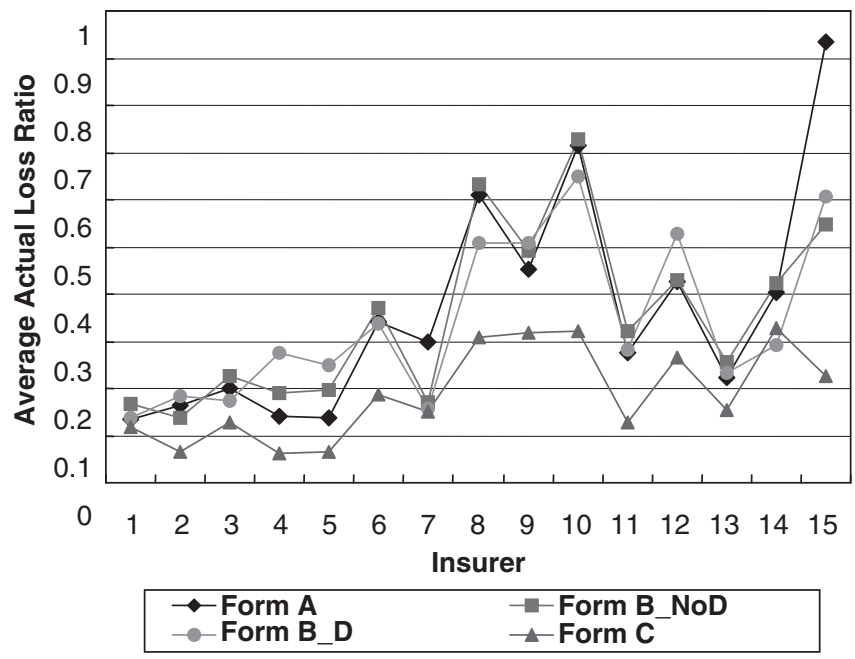

Figure 4. Distributions of average actual loss ratio of insurer by coverage.

factor obtained for Form A. Similarly, column 3 of Table 4 reveals that the basic premium is significantly different from the theoretical value for Form B_D.

Our findings indicate that the official formula and related parameters do not reflect the distribution of actual loss in policy year 2003. This result is not unexpected because, based on the actuarial principle, insurance premiums are determined ex ante using historical loss data. Ex post adjustments in either the basic premium or related coefficients are needed after additional loss data becomes available.

\section{Measuring the average loss ratio}

Since there is no nominal price competition in this market, the firms may compete in terms of services and underwriting. Therefore, it is interesting to examine operating performance of insurers. In this section, we use the complete policy data set and claims data to evaluate and compare the correlations between the actual loss ratios and types of coverage. On the basis of the size of loss ratios, we rank all insurers in descending order. We expect that insurer operation efficiency is consistent for all policy types. In other words, if insurers maintain a good loss ratio for one policy type, they should maintain similar performance in other contract types. To assess this conjecture, we examine the distributions of average loss ratio for all four coverage types for each insurer, as shown in Figure 4. It is clear that Form $\mathrm{C}$ has the lowest average loss ratio among insurers. In addition, the average loss ratios for all coverage types are closely correlated with the insurer. ${ }^{17}$

${ }^{17}$ Spearman rank correlation tests confirm these results. 


\section{Implications}

Our research leads to the conclusion that the rating structure for premiums is consistent with the pattern of losses for one coverage type but is inconsistent for the other three. It also suggests that the premium loadings are high.

The design of the rating formula appears consistent with observations from the United States, which generally show that for young drivers the accident rates decline rapidly with age, then level off, rising again as age increases, and that men tend to have higher accident rates than women. The applicability of the design to the Taiwan market may be misguided.

In the United States, the premiums for insurance are based on the characteristics of the highest rated driver in the household. In Taiwan, the premiums are based on the characteristics of the owner of the car. Thus a household can save substantial amounts of money by having the automobile registered in the name of the person in the family with the lowest premium, after considering the effect of age, gender, and prior claim history. Hence the rating formula may well have the effect of discriminating against young drivers, who for some reason, must declare themselves as car owners and against older people within the same family who own and actually drive their own car. A household can save about 10 per cent of the premium for automobile first party property damage by the simple ploy of having a car owned by a female, although the car is actually driven by a male of same age or an older male with claims history. The transfer of ownership from a male under 20 years of age to his mother or grandmother can reduce premiums by almost 50 per cent, assuming the claims histories are the same.

Drivers under 25 years of age can achieve savings of over 35 per cent by registering ownership of the vehicle to older members of the household. Older members can achieve smaller savings, and males can achieve savings of about 10 per cent by having the vehicles owned by females in the household.

The fraction of claims for property damage related to accidents in which the driver is not the owner of the vehicle is substantial. A clear implication is that the regulatory body should either reconsider the design of the formula to fit the conditions prevalent in Taiwan to improve the equity of the rating system, or revise the rules that relate the premium to the car owner.

The implications of the high loadings are more difficult to discuss because key data is not available. According to A.M. Best's Aggregates and Averages, in the United States, the average loading (the ratio of premiums to losses, minus one) for property damage to private passenger automobiles between 1989 and 2000 was 0.60. European loadings, estimated from the results of Cummins and Outreville, range from 0.38 to $1.11{ }^{18}$ These are much lower than the loadings observed in Taiwan. The implication is that the market may be inefficient, but we cannot be sure. In general the funds not used to pay losses will go to one of the following purposes:

1. Payment of the costs of settling claims.

2. Payment of commissions to intermediaries.

\footnotetext{
${ }^{18}$ Cummins and Outreville (1987).
} 
3. Payment of dividends to policy-holders.

4. Provision of other services to the policy-holders (for example, payment for or not questioning potentially fraudulent claims).

5. Payment of dividends to shareholders or retained earnings of the corporation.

6. Payment of higher than necessary compensation to insurance executives and other key personnel.

7. Subsidies for other lines of insurance. Private passenger liability insurance and commercial automobile coverage are candidates because the ratio of premium to losses appears to be higher for "all auto", which includes liability and commercial (as portrayed in the data of the Insurance Institute). Other lines could also be involved.

The data available does not permit the drawing of strong conclusions in this area, but some points are worth making.

The cost of settling claims in the U.S. is only about ten per cent of the cost of repairs, therefore Taiwan would have to be very different in this aspect to account for many of the differences in loading. Commissions in the U.S. average about 10 per cent of premiums; in Taiwan they appear to be considerably higher, maybe as high as 35 per cent, but that is not enough to account for loadings of 200 per cent, much less 500 per cent.

Dividends to policy-holders are not common in Taiwan. For Form $\mathrm{C}$ the loading is about five, meaning that the losses are about one-sixth of premiums. The cost of possibly fraudulent losses due to the $12^{\text {th }}$ month excess is roughly equal to one month of claims. Thus, overly generous compensation for these claims does not account for much of the high loading. For Forms A and B, the margin is roughly two and the excess cost of $12^{\text {th }}$-month claims is equal to about two months of claims, which is not enough to make a significant impact.

There appears to be some recognition that the premiums have been set too high, as basic premiums have been declining steadily for all types of coverage. If the original setting was too high, resulting in excessive profits, it might be expected that some companies at least would have begun to compete for market share by offering high commissions to agents. As long as the revenues after commissions were more than enough to pay for the losses and related overhead, the excess could be shared between the company personnel and the shareholders. Figure 4 indicates that the fraction of premiums used to compensate claims varies substantially among companies and types of coverage. For Forms A and B six of the 15 companies use less than 30 per cent of the premiums to pay for losses, four use more than 40 per cent, and five use between 20 per cent and 40 per cent. For Form C, six companies use less than 15 per cent of the premiums to cover losses, four use more than 30 per cent of the premiums for that purpose, and five use between 15 per cent and 30 per cent. This suggests that some companies have chosen to compete on the basis of commissions or services whereas others have opted for competition on the basis of compensation. ${ }^{19}$ Some have, apparently, found ways of increasing the awards to policy-holders, either by less stringent underwriting or by allowing payment of poorly substantiated and doubtful claims.

\footnotetext{
${ }^{19}$ Wang et al. (2010).
} 
S80

Subsidies across lines of insurance cannot be explored, even tentatively. With the current information, an analysis of the underwriting profit across lines would be required as a minimum. In any event the results suggest that the regulations of premiums for private passenger automobile physical damage should be reassessed carefully to bring premiums for all types of coverage in line with loss costs, and to discourage fraud and restore the business to a more sustainable level of competition.

\section{References}

Brown, R.L., Charters, D., Gunz, S. and Haddow, N. (2007) 'Colliding interests-Age as an automobile insurance rating variable: Equitable rate-making or unfair discrimination?' Journal of Business Ethics 72(2): 103-114.

Braver, E.R. and Trempel, R.E. (2004) 'Are older drivers actually at higher risk of involvement in collisions resulting in deaths or non-fatal injuries among their passengers and other road users?' Injury Prevention 10(1): 27-32.

Butler, P., Butler, T. and Williams, L.L. (1988) 'Sex-divided mileage, accident, and insurance data show that auto insurers overcharge most women', Journal of Insurance Regulation 6(3-4): 243-284, 372-420.

Chang, L. and Fairley, W. (1979) 'Pricing automobile insurance under multivariate classification of risks: Additive versus multiplicative', Journal of Risk and Insurance 46(1): 75-98.

Cheng, W. and Ng, Y. (1999) 'Intra-firm branch competition for a monopolist', Australian Economic Papers 38(3): $238-249$.

Coutts, S. (1984) 'Motor premium rating', Insurance: Mathematics and Economics 3(2): 73-96.

Cummins, J.D. and Outreville, J.F. (1987) 'An international analysis of underwriting cycles in propertyliability insurance', Journal of Risk and Insurance 54(2): 246-262.

Denuit, M. and Lang, S. (2004) 'Non-life rate-making with Bayesian GAMs', Insurance: Mathematics and Economics 35(3): 627-647.

Jee, B. (1989) 'A comparative analysis of alternative pure premium models in the automobile risk classification system', Journal of Risk and Insurance 56(3): 434-459.

Kelly, M. and Nielson, N. (2006) 'Age as a variable in insurance pricing and risk classification', The Geneva Papers on Risk and Insurance-Issues and Practice 31(2): 212-232.

Lemaire, J. (1995) Bonus-Malus Systems in Automobile Insurance, Boston, MA: Kluwer Nijhoff.

Li, C.-S., Liu, C.-C. and Peng, S.-C. (2007) Measuring automobile insurance fraud in Taiwan, Paper presented at the $11^{\text {th }}$ Asia-Pacific Risk and Insurance Association Annual Conference.

Li, C.-S., Peng, S.-C. and Liu, C.-C. (2008) 'Induced claims of unknown perils in automobile insurance: Empirical evidence in Taiwan', Academia Economic Papers 36(3): 249-275.

Stroinski, K.J. and Currie, I.D. (1989) 'Selection of variables for automobile insurance rating', Insurance: Mathematics and Economics 8(1): 35-46.

Wang, J.L. (2004) 'Asymmetric information problems in Taiwan's automobile insurance market: The effect of policy design on loss characteristics', Risk Management and Insurance Review 7(1): 53-71.

Wang, M., Wen, C. and Lan, L. (2010) The Geneva Papers on Risk and Insurance-Issues and Practice 35(2): 290-308.

Weisberg, H. and Tomberlin, T. (1982) 'A statistical perspective on actuarial methods for estimating pure premiums from cross-classified data', Journal of Risk and Insurance 49(4): 539-563.

Yip, K.C.H. and Yau, K.K.W. (2005) 'On modeling claim frequency data in general insurance with extra zeros', Insurance: Mathematics and Economics 36(2): 153-163. 


\section{About the Authors}

Chu-Shiu Li is Professor, Department of Economics, Feng Chia University, Taichung, Taiwan.

Chih Hao Lin has a PhD from the Department of Economics, Feng Chia University, Taichung, Taiwan.

Chwen-Chi Liu is Professor, Department of Risk Management and Insurance, Feng Chia University, Taichung, Taiwan.

Emilio Venezian is Adjunct Professor, $\mathrm{PhD}$ programme in Business, Feng Chia University, Taichung, and at Chaoyang University of Technology, Wufong, both in Taiwan. He retired from the Department of Finance and Economics, Newark and New Brunswick, Rutgers University, U.S.A. 